\title{
Enquête
}

Archives de la revue Enquête

1 | 1985

À propos des cultures populaires

\section{Dominocentrisme et dominomorphisme}

\section{(2) OpenEdition}

1 Journals

Édition électronique

URL : http://journals.openedition.org/enquete/42

DOI : $10.4000 /$ enquete.42

ISSN : 1953-809X

Éditeur :

Cercom, Éditions Parenthèses

Édition imprimée

Date de publication : 2 avril 1985

\section{Référence électronique}

" Dominocentrisme et dominomorphisme », Enquête [En ligne], 1 | 1985, mis en ligne le 26 juin 2013,

consulté le 30 avril 2019. URL : http://journals.openedition.org/enquete/42 ; DOI : 10.4000/enquete.42

Ce document a été généré automatiquement le 30 avril 2019 


\section{Dominocentrisme et dominomorphisme}

C. GRIGNON.- Nous avons déjà remarqué, lors de la première séance, que l'information délivrée par la sociologie du goût tend à se raréfier à mesure que l'analyse descend dans la hiérarchie sociale, qu'elle passe de la culture de « l'élite » à la « culture moyenne » et de la « culture moyenne » à la culture « des masses »; nous avions attiré l'attention sur le paradoxe d'un balisage de l'espace social qui, réduisant le distinctif au sélectif et ne retenant comme pertinentes que les pratiques les plus rares, tend à constituer l'opposition entre la base et le pôle, entre la périphérie et le foyer, comme principe unique d'orientation et conduit inévitablement à desserrer la trame de l'analyse à mesure que la population des faits sociaux et des traits culturels augmente. Par une aberration comparable à celles qu'engendrent les techniques de projection utilisées par les cartographes, les cartes de l'espace sociologique produites selon ce principe présentent, comme on le sait, une image complètement inversée du territoire social, la description minutieuse et fouillée des régions "polaires » contrastant fâcheusement avec les zones presque blanches qui signalent, dans le bas des feuilles, les terres inconnues - pour ne pas dire interdites - habitées par les classes populaires. Tout se passe comme si l'observateur, placé sur la pointe de la pyramide sociale, perdait son pouvoir de discernement à mesure que son regard plonge vers la base de celle-ci : la raréfaction de l'information pertinente va de pair avec l'indifférence aux différences, aux variations et aux oppositions dont la connaissance permettrait seule de construire l'espace social des goûts populaires. Le schéma suivant peut aider à comprendre comment la perspective légitimiste engendre l'illusion de l'homogénéité des classes et des cultures dominées : 


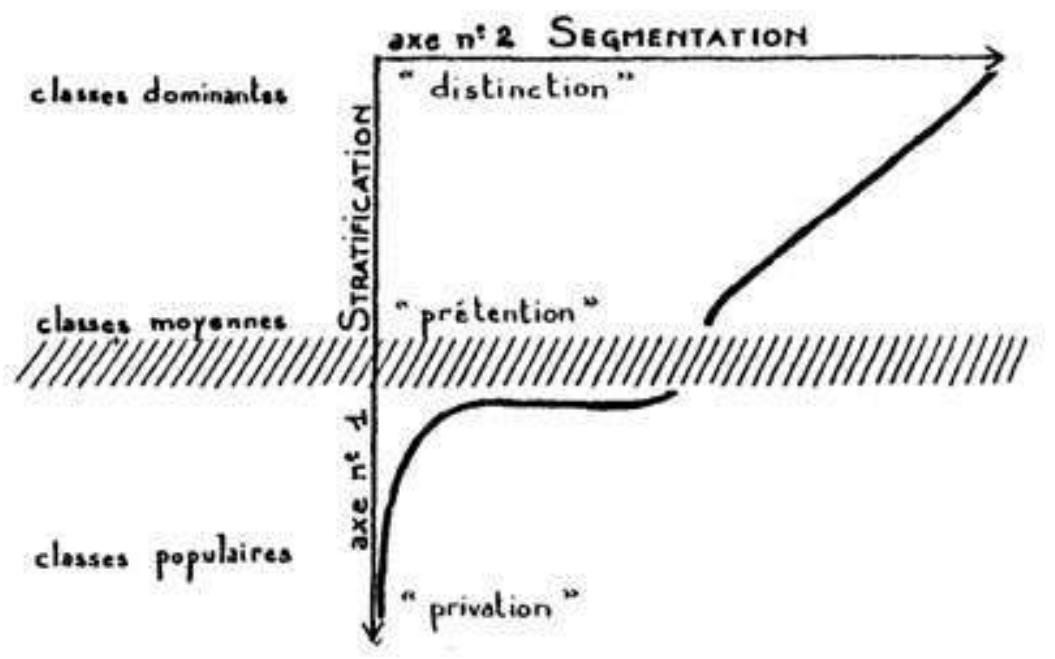

Les axes 1 et 2 (méridiens et parallèles des "cartes sociologiques ») représentent les coordonnées de l'espace social ; l'axe 1 correspond à la relation de domination entre les classes et entre les cultures, à la hiérarchie «verticale » des classes et des couches, bref à la stratification sociale et culturelle; le second axe, horizontal, correspond à la segmentation, aux différences qui, à chaque palier de la structure sociale et à l'intérieur de chaque classe, permettent de distinguer des fractions de classe (et des goûts ou des souscultures de fraction). On pourrait dire aussi que le premier axe est celui des indicateurs de niveau (niveau de revenu, niveau de diplôme, etc..) et en premier lieu celui du niveau de vie, l'axe horizontal correspondant aux différences dans les conditions de vie et dans les modes de vie (par exemple aux variations liées au métier, à l'habitat, à la résidence, etc.). On voit que tout repérage de la position occupée par un groupe (ou par une constellation de pratiques ou de goûts) dans l'espace social devrait permettre de le situer aussi bien par rapport au second axe (qui n'est pas nécessairement " secondaire ») que par rapport au premier, et de préciser aussi bien son appartenance de fraction que son appartenance de strate ou de couche. En fait la capacité des analyses d'inspiration légitimiste à dégager et à construire l'axe de la segmentation sociale, à décrire et à interpréter les différenciations horizontales des cultures de classe, varie considérablement en fonction de la position occupée sur l'axe vertical par les groupes (ou par les goûts) qu'elle prend pour objet. Au niveau des classes dominantes, l'analyse, comme on sait, multiplie les distinguo et parvient à établir un réseau serré de relations entre les variations des goûts et les positions occupées par les différentes fractions de classe sur un axe horizontal allant $d u$ "pôle intellectuel» au "pôle économique ». À l'étage au-dessous, la sociologie des classes et des cultures moyennes tend à glisser vers une sociologie de la petite bourgeoisie et du goût petit-bourgeois. Au niveau de ces "bourgeois en petit ", plus riches d'aspiration et de "prétention » que de capital, l'opposition entre fractions intellectuelles et fractions possédantes n'existe plus que d'une manière virtuelle et pour ainsi dire en pointillé : instituteurs et petits commerçants se définissent moins les uns par rapport aux autres que par rapport à leurs homologues et modèles de la « vraie » bourgeoisie, professeurs et industriels. L'essentiel de l'analyse, qui tend déjà à se rabattre sur l'axe vertical, porte sur les différences de niveaux qui séparent les petits bourgeois des grands bourgeois, le goût moyen du goût dominant ; ce n'est sans doute pas un hasard si le vocabulaire légitimiste se gonfle à ce niveau-là de mots- 
partisans, spécialisés dans la dénonciation de ces écarts, ouvertement bardés de mépris de classe et rebelles à la neutralisation scientifique, comme "demi-habiles ", « simili ", «prétention », «faisant-fonction », etc.

3 Le sociologue légitimiste avisé et cohérent s'arrête là et s'abstient de descendre : il se contente de jeter un coup d'œil, à la rigueur quelques coups de sonde, dans les profondeurs où les classes populaires sont reléguées. Tel le Hugo des Misérables, il pourrait s'écrier : «Ici nous renonçons à peindre!» ou encore, tel le César de Pagnol voulant prévenir paternellement les audaces éventuelles de Marius océanographe : « Là où c'est profond, laisse un peu mesurer les autres! ». Tout se passe en effet comme si les lueurs de sa théorie étaient incapables de dissiper les ténèbres qui s'épaississent à mesure qu'on s'éloigne du foyer lumineux de la culture légitime. Définie exclusivement par référence au goût dominant, c'est-à-dire négativement, en termes de handicaps, de limitations, d'exclusion, de privations, d'absence de choix, de non-consommations et de non-pratiques, etc., la culture populaire apparaitt nécessairement, dans cette perspective, comme un ensemble indifférencié de manques, dépourvu de repères propres, à l'intérieur duquel on peut tout juste essayer de distinguer des strates de densité symbolique décroissante, allant de la "quasi-simili-culture » des couches frontalières de la petite bourgeoisie (élite ouvrière, ménages mixtes ouvriers/employées, anciens ouvriers établis à leur compte, etc.) à la non-culture du sous-prolétariat et des « exclus ».

4 Ce schéma fait évidemment penser à des analyses contemporaines; mais la meilleure manière de le commenter et de l'illustrer est sans doute de se reporter à des textes plus anciens, qui font mieux voir la genèse et le fonctionnement des schèmes légitimistes. Ainsi la théorie «focaliste» de la vie sociale et de la culture qu'on trouve chez M. Halbwachs fait apparaitre l'ethnocentrisme, ou plus précisément le dominocentrisme qui continue de hanter, sous une forme plus déguisée et plus déniée, les descriptions légitimistes du goût populaire. Il est assez facile de reconstituer l'image-souche à partir de laquelle s'engendrent les schèmes halbwachsiens : elle affleure dans maints passages. L'« édifice social » évoque à la fois la ville et la famille : il rayonne, en couches successives et concentriques, autour d'un foyer central où la vie sociale est plus dense, plus intense, plus compliquée, plus cultivée et plus diversifiée. Il ressemble assez à une sorte d'amphithéâtre inversé, dont la scène occuperait le sommet: sur la scène et sur les gradins du haut, les classes dirigeantes et dominantes, celles qui participent le plus activement aux diverses formes de la vie sociale, politique, religieuse, culturelle; sur les gradins du bas, les classes moyennes, spectatrices, rarement actrices ; à l'écart, en dehors des barrières, occupées à des tâches matérielles, exclues de la vie sociale, les classes populaires.

5 Si Halbwachs peut placer son observatoire au centre même du «foyer » et adopter sans faux-fuyants et sans contorsions un point de vue qui coïncide exactement avec celui des dominants pour décrire les rapports de domination entre les classes, c'est sans doute parce que ses travaux sont antérieurs, du moins dans leur inspiration d'origine, à la rupture relativiste dont parlait Passeron; au moment de ses débuts (sa thèse sur La classe ouvrière et les niveaux de vie date de $1912^{1}$ ), la rupture de l'anthropologie avec l'évolutionnisme n'a pas encore été rapatriée des cultures indigènes des sociétés coloniales sur les cultures populaires. Ainsi Halbwachs établit une double correspondance, d'une part entre les classes populaires, les besoins biologiques élémentaires ou "primaires" (comme il dit et comme on n'a pas cessé de dire), et les consommations et les goûts les plus communs, et à l'opposé - sur les gradins du haut - 
entre les classes dominantes, les besoins les moins «matériels », les biens les plus rares et les goûts les plus épurés :

«Les aliments, c'est le premier besoin : primum vivere [...] si nous nous plaçons au niveau de la classe ouvrière, il faut bien dire qu'il n'y a pas de besoins qui aient davantage un caractère physique, organique, et où le côté social proprement dit passe plus à l'arrière-plan ${ }^{2}$. »

"À mesure qu'on passe des groupes où la vie sociale est plus intense, mieux organisée, plus compliquée, à mesure aussi on voit les besoins se vider de tout leur contenu "primitif", s'émousser et presque s'évanouir les impressions organiques naturelles et les satisfactions qui en dérivent ${ }^{3}$.»

Il met du même coup au jour, dans sa simplicité, le présupposé soigneusement enfoui sur lequel repose encore, y compris dans ses dernières complications, la sociologie légitimiste des goûts : l'ordre symbolique (hiérarchie des goûts) correspond à la fois à l'ordre social (hiérarchie des classes) et à l'ordre naturel (hiérarchie des besoins). Franchir la barrière qui sépare les classes moyennes des classes populaires, c'est sortir de la sphère de la culture pour se perdre dans la «nature ». La contradiction entre la démarche empirique suivie par Halbwachs (qui entend aller voir pour de bon ce qui se passe dans la classe ouvrière) et son projet théorique montre sur un exemple concret qu'une sociologie légitimiste de la culture n'a rigoureusement rien à dire sur la culture et sur les goûts populaires (du moins tant qu'elle entend demeurer cohérente, et, à sa manière, scientifique et que, s'en tenant à la perspective misérabiliste, elle se retient de basculer dans le populisme) : si la culture populaire est pour elle indescriptible, c'est parce qu'elle est impensable. Dans la perspective halbwachsienne le mode de vie des classes populaires se déduit directement du niveau de vie et en définitive s'y réduit; alors que l'ambition minimale de tout sociologue qui s'engage dans un travail empirique de description est de faire apparaître des variations systématiques (et si possible d'en rendre compte), Halbwachs, qui interroge son matériel au moyen des codes engendrés par les schèmes focalistes, ne peut pas, quelle que soit la richesse et la diversité des données dont il dispose, ne pas aboutir au constat de l'homogénéité de la classe ouvrière :

«Plus nous avons étudié cette classe [la classe ouvrière], plus nous avons reconnu l'uniformité et la simplicité de ses tendances et à quel point les réactions de ces groupes sont mécaniques et limitées. On pourrait penser que la diversité des métiers et la diversité des revenus séparent la classe ouvrière en une quantité de groupes [...] si bien que la classe ouvrière serait elle-même une société très complexe [...] Mais toute notre étude prouve le contraire. Si nous nous étions proposé d'étudier les besoins sociaux et les activités sociales sous leurs formes les plus achevées, nous aurions dû les observer dans les parties les plus hautes de la société. Mais nous voulions étudier les classes : or il n'y a sans doute pas de classe plus homogène, précisément parce que la vie sociale y est plus réduite, moins compliquée, et aussi parce que l'intervalle qui la sépare des autres groupes, sous ce rapport, est très marqué, que la classe ouvrière ${ }^{4}$.»

Reprenons la démarche empirique de Halbwachs, mais dans un esprit moins contraire à son aboutissement, et essayons de voir par quels moyens empiriques on pourrait opérer des distinctions à l'intérieur des classes populaires et faire apparaître des variations du mode de vie et des goûts populaires. Voyons pour commencer les ressources offertes par l'analyse secondaire. Dans le cas de la paysannerie, on sait que les recensements et les enquêtes de consommation réalisés par l'INSEE regroupent jusqu'à maintenant tous les ménages dont le chef est exploitant agricole dans une CSP unique. En ce qui concerne la stratification sociale et les problèmes qui lui sont liés (dispersion des modes de vie paysans, existence d'invariants trans-couches permettant de définir un mode de vie 
paysan relativement autonome, opposition entre couches modernistes et couches traditionnelles, etc.) il faut donc se débrouiller ; soit qu'on utilise les enquêtes technicoéconomiques sur l'agriculture (comme le RGA) pour construire la hiérarchie sociale des exploitants à partir de la hiérarchie économique des exploitations et pour mettre le découpage de la paysannerie obtenu par ce moyen (en général en petits, moyens et gros paysans) en relation avec les indicateurs de niveau de vie et de conditions de vie (célibat, nombre d'enfants, nombre d'actifs sur l'exploitation, etc.) que livrent, assez parcimonieusement et souvent irrégulièrement, ces enquêtes; soit qu'on essaie de distinguer différentes couches d'agriculteurs au moyen des indicateurs économiques (taille économique et orientation technico-économique des exploitations) que comportent certaines enquêtes de consommation. S'agissant de distinguer non plus des couches mais des fractions, et des «sous-cultures» de fractions, la liaison, exceptionnellement forte dans le cas de la paysannerie (où l'exploitation et le ménage demeurent relativement indivis) entre le type de production et les conditions de travail, et entre les conditions de travail et les conditions de vie, devrait permettre une utilisation plus directe et plus poussée des indicateurs ou des enquêtes à caractère technicoéconomique. Tout donne à penser, par exemple, que le mode de vie des cultivateurs diffère de celui des éleveurs, moins affranchis par la technique des contraintes naturelles; que parmi les éleveurs, il faut encore distinguer entre le mode de vie des spécialistes du "hors-sol», aviculteurs et producteurs de porcs, et celui des éleveurs traditionnels, que parmi ceux-ci les producteurs de viande s'opposent aux producteurs de lait, soumis à la servitude quotidienne de la traite, etc.

8 On pourrait aussi interpréter les différences régionales, que les enquêtes mettent bien en évidence (au prix, il est vrai, de regroupements administratifs parfois artificiels), comme des indicateurs de segmentation de la paysannerie; on peut même dire que les différences régionales constituent un principe spécifique de segmentation de la paysannerie, dans la mesure où elles sont, dans son cas, plus marquées et plus pertinentes que dans celui de n'importe quelle autre classe, à la fois pour des raisons techniques (contraintes climatiques et pédologiques) et pour des raisons culturelles. La question des relations entre déterminismes sociaux et déterminismes spatiaux se pose différemment et avec une force inégale selon qu'on a affaire à des catégories purement socioprofessionnelles, dépourvues d'épaisseur historique, comme par exemple les cadres, ou à des groupements que leur ancienneté enracine dans des traditions à base régionale et locale (le rapport des forces explicatives entre la sociologie et ses concurrentes, l'histoire et la géographie humaine, change déjà beaucoup quand on passe de la classe ouvrière à la paysannerie). Le cas des paysans montre en outre que la position d'un groupe (ou d'une constellation de pratiques) sur l'axe des fractions n'est jamais tout à fait indépendante de sa position sur l'axe vertical de la stratification sociale : il y a des régions riches et des régions pauvres, des spécialisations réservées aux gros agriculteurs (comme la céréaliculture) et des productions-refuge., abandonnées aux petits paysans (comme la polyculture-élevage); nous aurons sans doute l'occasion de revenir sur cette question.

En ce qui concerne la classe ouvrière la situation est inversée. Le code des CSP, qui distingue entre les manœuvres, les OS, les ouvriers qualifiés et les contremaîtres invite à l'analyse en termes de niveaux de vie et de stratification sociale. Si l'on veut passer à l'étude de la segmentation, il faut soit utiliser des archaïsmes du code des CSP, qui isole les mineurs et les marins, soit procéder à des traitements secondaires qui permettent (à condition d'effectuer de nouveaux tris) de fractionner la catégorie «ouvriers» (ou les 
sous catégories "OS", " manœuvres", etc.) selon le type d'habitat (rural/urbain) ou selon la région de résidence. On peut aussi essayer, pour les enquêtes de consommation et pour les recensements (qui fournissent les informations de base sur les conditions de vie), de combiner la catégorie socioprofessionnelle avec le secteur ou la branche d'activité ; en se donnant ainsi le moyen de distinguer entre les ouvriers du bâtiment, du textile, de la métallurgie, etc. on pourrait commencer à explorer la relation entre le mode de vie et les différentes «cultures de métier ». Bien que les enquêtes de mobilité sociale (comme les enquêtes $F Q P$ de l'INSEE) saisissent par définition des relations inter-classes et intercouches, elles peuvent être aussi utilisées pour mettre en évidence le lien entre l'origine sociale et l'appartenance de fraction ; c'est ainsi, par exemple, que $C$. Thélot a montré que les ouvriers d'origine paysanne ont des chances nettement plus élevées que les ouvriers d'origine ouvrière de travailler dans le bâtiment ou dans les transports ${ }^{5}$.

Revenons à l'alimentation populaire, dont j'ai parlé dans la première séance et voyons, à propos de ce travail, comment on peut essayer de mettre en évidence des "goûts de fraction ». Une enquête par questionnaire, que j'ai menée parallèlement à l'analyse secondaire des données recueillies par l'INSEE, montre que les pratiques alimentaires des ouvriers varient en fonction de leur résidence (urbaine ou rurale), et, ce qui est moins attendu, et sans doute plus intéressant, de leur origine sociale. Ainsi les ouvriers d'origine paysanne recourent plus fréquemment que les autres ouvriers, et notamment que les ouvriers d'origine ouvrière, à l'approvisionnement direct (notamment pour la viande et pour les volailles); ils sont plus nombreux, proportionnellement, à faire du jardinage, à avoir un potager, à posséder un congélateur, à faire des conserves ou de la congélation familiale, etc. Inversement les ouvriers d'origine ouvrière s'approvisionnent plus souvent dans les grandes surfaces, sont moins réticents à l'égard des produits "industriels " comme la margarine; leur style d'alimentation est moins traditionnel, moins enraciné dans les traditions locales, plus urbanisé ; on pourrait sans doute montrer qu'il fait partie d'un art de vivre - ou de survivre - différent, dont participent aussi les manières de se loger, de s'habiller, de se distraire, de se soigner, etc. et qui se rapproche davantage de la " culture ouvrière industrielle », depuis longtemps dépaysannisée et urbanisée, que décrit R. Hoggart. L'enquête permet encore de distinguer entre l'alimentation des ouvriers issus de familles de petits commerçants ou d'artisans, qui se rapproche de la variante paysanne de l'alimentation ouvrière, et l'alimentation des ouvriers originaires de familles d'employés, qui constitue la variante la moins paysanne, la moins populaire, la plus petite-bourgeoise de l'alimentation ouvrière. On voit qu'elle fait apparaître des pôles, un couple d'oppositions (alimentation ouvrière paysanne/alimentation ouvrière ouvrière) et des variations qui se laissent ordonner systématiquement par rapport à ces pôles. La taille de l'échantillon ne permettait malheureusement pas de croiser l'origine sociale et la résidence. Mais toute donne à penser que ces variations ne renvoient pas seulement à des conditions et à des milieux de vie différents, mais aussi à des habitudes, à l'expérience, accumulée et transmise, de ces conditions de vie et de la manière dont on peut s'en accommoder.

11 Essayons d'aller un peu plus loin dans l'interprétation de ces variations. C'est déjà une manière de rompre avec l'ethnocentrisme de classe que d'essayer de transporter les instruments d'analyse à l'extrémité opposée de l'espace social et de l'espace des goûts, et de voir dans quelle mesure, et moyennant quelles adaptations on peut transposer au cas des classes populaires et de la culture pratique le schème d'explication utilisé pour rendre compte de la genèse et de la diversité sociales des goûts de la classe dominante et des 
goûts cultivés: les goûts sont une manifestation, parmi d'autres, d'un système de dispositions qui varie en fonction des propriétés des groupes (ethos de classe, de fraction, etc.) et des propriétés liées à l'origine et à la trajectoire sociales des agents (habitus). Examinons les obstacles que rencontre cette transposition. En premier lieu, on voit bien que les «propriétés » sociologiques des dominants se déduisent sans mal de ce qu'ils possèdent, argent, relations, diplômes, positions de pouvoir, etc. Mais peut-on encore parler des propriétés de ceux qui ne possèdent rien (ou presque rien, et de toute façon, bien moins que les autres)? Comment le faire sans escamoter la distance qui sépare les dominés des dominants?

On peut d'abord se placer au niveau des conditions matérielles d'existence et essayer de montrer que les variations du goût populaire correspondent à des configurations, différentes selon les groupes et selon les milieux, de contraintes et de ressources, de handicaps et de contre-handicaps. Par exemple, habiter la province, dans un pavillon situé dans cette zone indécise qui n'est pas encore la banlieue mais qui n'est plus la vraie campagne, c'est à la fois avoir de l'espace, «être au large », et « être loin de tout », avec toutes les conséquences que cela peut avoir sur l'organisation de la vie quotidienne et sur l'économie domestique ; à l'inverse, habiter la région parisienne, c'est à la fois "passer son temps à courir », et "avoir tout sous la main». Remarquons tout de suite que la propriété essentielle de ces propriétés du milieu est sans doute leur ambivalence ; loin de se réduire à la description linéaire d'un système de contraintes et de limitations déterminant d'une manière univoque et mécanique le comportement des agents, leur inventaire contradictoire appelle en permanence une double lecture. Ainsi le cadre de vie, et même le cadre de travail, sont à la fois subis et choisis : subis dans la mesure où ils sont liés à une position qui est elle-même l'aboutissement d'une trajectoire sociale et d'un " destin "; choisis, dans la mesure où ils correspondent aussi à une série de "stratégies " visant à infléchir cette trajectoire et à obtenir des conditions de vie aussi peu éloignées que possible des habitudes et des goûts contractés dans le milieu d'origine (la possibilité de déployer ces stratégies et la disposition à le faire variant elles-mêmes selon les milieux et selon les groupes) ; ainsi, si les ouvriers d'origine paysanne habitent plus souvent dans des communes rurales que les ouvriers d'origine ouvrière, c'est à la fois parce qu'ils ont des chances plus faibles d'« accéder » à la résidence citadine (qu'ils évitent) et parce qu'ils ont des possibilités plus grandes de conserver une résidence rurale (qu'ils "préfèrent »). De même on peut décrire les comportements liés à la résidence ou au type d'habitat comme des "réponses" passives a des impossibilités pratiques limitant l'éventail des choix et l'initiative des agents, ou comme des activités visant à aménager la «niche écologique » et à lui faire rendre le maximum (ce qui est sans doute la définition même du «bricolage » populaire); ainsi l'achat d'un congélateur, dans le cas des paysans ou des ouvriers ruraux, peut aussi bien être lu comme une obligation liée à l'impossibilité de s'approvisionner sur place à bon compte, que comme une manière de mettre à profit les possibilités pratiques offertes par la situation (autoconsommation, jardinage, approvisionnement direct) ; les "goûts de proximité » peuvent être considérés aussi bien comme des « choix forcés » inscrits dans la répartition géographique des points de vente et dans la routine des parcours quotidiens, c'est-à-dire négativement, comme des " goûts d'éloignement " (on se fournit chez Esso parce que Shell ou Mobil sont trop loin) ou, à l'inverse, comme des non-choix délibérés (" pas la peine de se casser la tête, ça vient de la même citerne »). Et chacune des pratiques liées à l'exploitation forcée des possibilités offertes par le cadre de vie peut et doit à son tour être décrite d'une manière qui rend compte de son ambivalence : le jardinage ou la congélation domestique demandent à être 
décrits à la fois comme une détente et comme une corvée, comme un goût et comme du sur-travail, comme ce dont les classes dominantes sont dispensées, et, comme ce dont elles sont exclues, etc.

On peut aussi tenter de repérer, au niveau des groupes et des agents, des propriétés positives susceptibles de jouer le même rôle, pour l'explication des variations du goût populaire, que les différentes espèces de «capital » pour l'explication des variations du goût dominant. De ce point de vue, la petite propriété, le petit patrimoine des ouvriers issus de la paysannerie (ou du commerce et de l'artisanat ruraux) peuvent être considérés comme l'homologue du capital économique des fractions possédantes de la classe dominante ; la culture professionnelle, la culture de métier (qu'on rencontre plutôt chez les ouvriers qualifiés et dans l'élite ouvrière) correspond au «capital culturel » des fractions intellectuelles; enfin, par les fonctions dont il s'acquitte (entraide, solidarité, placement des jeunes, «choix du conjoint», intégration et reproduction des groupes, etc.) le réseau de relations à base locale, familiale, professionnelle ou militante fait beaucoup penser au «capital social ». Voici donc la triade au complet, descendue du Capitole et remontée sur l'Aventin. On pourrait pousser plus loin l'homologie : de même qu'on peut distinguer entre plusieurs sous-espèces de "capital culturel », on pourrait distinguer, à l'intérieur de la " culture de métier ", entre la culture professionnelle et la culture militante, entre la culture traditionnelle, transmise par l'apprentissage, la culture technique "savante ", transmise par l'École, et la culture - ou le folklore - de l'atelier (c'est à cette variété que se réfère D. Poulot). Mais, là encore, il s'agit de propriétés ambivalentes, qu'il faut s'attacher à décrire et à utiliser comme telles. Ainsi, la culture technique constitue à la fois un acquis, une "propriété » conquise par la classe ouvrière et une forme de culture dominée qui, outre qu'elle sert à la sélection de l'élite ouvrière, peut induire une forme particulière de reconnaissance des hiérarchies culturelles dominantes ; on pourrait sans doute montrer que le mode de vie et les goûts des ouvriers d'origine paysanne correspondent à une combinaison, particulièrement conflictuelle, de dispositions liées à l'héritage et à la petite propriété foncière et immobilière, et de dispositions liées à l'expérience de la prolétarisation et à la disparition de leur classe et de leur milieu d'origine.

Deux remarques pour conclure cet exposé préliminaire (qui est plutôt un préliminaire trop exposé) :

1. L'alimentation populaire se situe au point de rencontre entre la vie matérielle et la vie symbolique; il n'est pas de consommation ni de pratique qui ne renvoie à la fois d'une part au revenu, aux conditions de vie et de travail, et, d'autre part, à des habitudes, inscrites dans les traditions locales et dans les "sous-cultures" de groupe, à des représentations "indigènes" (relatives par exemple à la convenance des différents aliments en fonction du sexe, de l'âge, du métier) et à des modèles en provenance de la culture dominante (normes d'hygiène, définition de l'excellence corporelle, modes en matière de régime, etc.). Travailler sur l'alimentation populaire conduit et contraint à se poser le problème des relations entre l'explication par les dispositions matérielles du milieu et l'explication par les dispositions symboliques des agents et des groupes et à procéder, du même coup, à l'examen et à la mise à l'épreuve des instruments conceptuels et des opérateurs construits à partir de l'opposition entre le «matériel» et le « symbolique » (comme par exemple "goûts de liberté »/ " goûts de nécessité », « style de vie pour-soi »/《s style de vie en-soi », etc.). Toute la question est d'arriver à faire leur juste place aux déterminismes matériels, et notamment aux déterminismes matériels négatifs 
(observons au passage que les déterminismes matériels n'ont pas le monopole de la " négativité »: on peut dire en effet que l'alimentation populaire se trouve prise entre un ensemble d'impossibilités - ce qu'on ne peut pas manger - et un ensemble d'interdits - ce qu'il ne faut pas manger). Sous peine d'assimiler purement et simplement l'alimentation populaire à l'alimentation dominante, la culture pratique à la culture cultivée, la vie domestique aux comportements ostentatoires, il faut se garder de les oublier en recherchant à tout prix la complication et la sublimation (comme n'y invite que trop la position humiliée de l'objet dans la hiérarchie des sujets de recherche). Mais il faut aussi éviter le double piège de l'économisme et de l'écologisme. Outre que la reconstitution exclusive des limites que les conditions matérielles imposent au goût populaire n'apporte, on l'a vu, rien de nouveau par rapport à la connaissance spontanée qu'un bon informateur, ménagère avertie ou expert en combines, peut avoir de son univers pratique, on ne voit pas pourquoi la sociologie du goût populaire devrait, elle, se contenter de trouver son Maurice Rheims. Ou alors il faut dire clairement qu'on reconnait que de la vie pratique, il ne peut y avoir qu'une connaissance pratique. Changer aussi radicalement d'outillage conceptuel, de dispositif explicatif quand on passe des goûts cultivés aux goûts matériels, des classes dominantes aux classes dominées est encore une manière de reconnaître implicitement l'altérité radicale des classes populaires, la discontinuité de l'espace social (de part et d'autre du "fossé halbwachsien») et la discontinuité de l'espace symbolique: d'un côté l'embarras du choix, les goûts désintéressés, le luxe superflu de la "broderie » symbolique; de l'autre la pression des « besoins primaires », les goûts de " proximité » et d'« utilité », le couperet de la nécessité nécessiteuse.

2. On peut cependant se demander si le transfert des schèmes utilisés pour rendre compte des goûts dominants ne perd pas de sa pertinence et de sa force explicative à mesure qu'on descend dans la hiérarchie sociale et qu'on va vers les couches les plus démunies et les plus handicapées de la classe ouvrière et de la paysannerie. Même si l'on peut récupérer des «propriétés » ailleurs que dans l'élite ouvrière (comme le petit patrimoine des ouvriers d'origine paysanne, qui sont plus souvent OS que les ouvriers d'origine ouvrière), ne devient-il pas de plus en plus difficile de trouver des « équivalents » des différentes espèces de "capital»? Les contraintes et les limitations du cadre de vie ne tendent-elles pas à l'emporter sur les ressources et sur les contre-handicaps? Comment faire quand les conditions de vie deviennent quasi «invivables»? N'arrive-t-il pas toujours un moment, lorsqu'on en vient aux cas-limite - sous-prolétariat, "exclus ", marginalisés, précarisés - où les instruments forgés pour l'étude des goûts dominants deviennent inutilisables et où il faut bien essayer d'en imaginer d'autres, plus capable de rendre compte de la diversité des pratiques par l'intermédiaire desquelles les plus démunis s'efforcent de survivre et de se mettre « au minimum du pire »?

17 J.-C. PASSERON.- La transposition des concepts de «capital économique » et de «capital culture ou social » que Grignon vient d'opérer sous nos yeux - transposition qui vise à appliquer à la description des facteurs produisant la différenciation au sein des classes dominées des concepts forgés pour objectiver en le détaillant "l'avoir » des classes dominantes - me paraît assez piquante en ce qu'elle pose un problème pervers sur les fonctions de la théorie sociologique, ou, plus exactement, un problème d'inversion inattendue de l'« effet pervers " généralement attaché à cette transposition. Nous disions en commençant le premier séminaire - et le schéma bi-pyramidal de Grignon nous démonte la ruse de cette machine infernale - que la démarche légitimiste ou «focaliste ", 
qui consiste à décrire les comportements culturels des classes populaires en assurant ses prises conceptuelles - je paraphrase - sur la fine pointe de la pyramide sociale (base de la pyramide légitime offrant de nombreuses saillies) pour explorer sa base démographique conduisait le sociologue à un dérapage incontrôlé où ne s'offre plus à son pied que la pointe exiguë de la pyramide des différences légitimes : cette sociologie spéculaire des classes dominées ne peut qu'abolir dans l'indifférenciation du manque toutes leurs "propriétés ». En reconnaissant généreusement aux dominés le droit d'émarger à la même théorie de la culture que les dominants, la théorie de la légitimité culturelle qui doit reprendre pour en décrire l'arbitraire le langage de la légitimité sociale aboutit, en fait, à refuser aux dominés tout autre droit théorique que celui de se trouver enfermés dans une condition sans «qualités » ni « distinctions » : effet pervers des plus classiques où la bonne volonté d'objectivation de l'arbitraire culturel dominant semble produire par une dérive nécessaire l'effet contraire à celui qu'elle vise puisque l'arbitraire décrit finit par s'imposer arbitrairement à toute description.

Mais voilà que votre démarche montre que ce n'est pas une fatalité inhérente à toute transposition analogique des "traits distinctifs » du dominant à la catégorisation du dominé. Ici, la transposition "marche» en ce sens qu'elle révèle un pouvoir d'enrichissement de la description et de l'explication, en restituant aux pratiques populaires en même temps qu'un terrain d'expression des différences une logique d'engendrement de ces différences. Bref, votre conceptualisation par "équivalence " produit des connaissances parce qu'elle oblige à des tâches empiriques de discrimination et de mise en relations. Il n'y a jamais lieu de faire la fine bouche devant une démarche théorique qui crée des exigences de travail empirique. Tant qu'une analogie «marche " laissons-la aller, et même filer ses métaphores; il ne faut l'arrêter qu'au point où son langage interdirait de construire un autre programme de travail empirique. Aussi bien suis-je en balance devant votre démarche d'équilibriste avec une question dont je ne sais trop à quel moment il faudra vous la lancer, si je ne veux pas risquer d'interrompre un exercice profitable mais périlleux de trop durer. Je la dépose cependant au bord de la piste : votre transposition - qui est à la fois élargissement et spécialisation du concept de « capital » afin de l'adapter à la description des « avoirs » populaires - ne risque-t-elle pas d'interdire l'appréhension d'autres "propriétés » populaires que celles qui se prêtent analogiquement à être saisies comme "capitaux " (" petits " ou «équivalents») ? Ne vient-il pas un moment où cette transposition enferme la description dans la tâche de répertorier les seuls avoirs du pauvre qui se laissent décompter en monnaie de riche ? $\mathrm{Ne}$ risque-t-on pas de racler les fonds de tiroir en oubliant d'ouvrir les placards ? Par cette question, je caricature évidemment votre démarche, puisque avec les «cultures de métier » par exemple, c'est bien autre chose que la menue monnaie du capital culturel légitime que vous décrivez; mais justement, la conceptualisation de tels avoirs en termes de capital n'affaiblit-elle pas la description de la manière dont ils produisent leurs effets différenciateurs? Autrement dit, la liaison entre les deux moments du raisonnement que vous venez de tenir reste, à première vue, quelque peu paradoxale: partant de la nécessité de ne pas s'enfermer dans la sociologie privative des cultures populaires qu'engendre l'«illusion d'Halbwachs", ce sont finalement des analyseurs réglés sur la structure et la logique de fonctionnement des avoirs dominants que vous utilisez pour objectiver les propriétés des dominés - tout en imposant, je le reconnais, à ces outils d'importation un petit recyclage humoristique. 
C. GRIGNON.- Il faut en effet reconnaître et marquer les limites de l'exercice. Je ne reproche pas à la sociologie du goût d'inspiration légitimiste de s'être donné les moyens d'analyser les variations du goût dominant; j'essaie seulement de montrer pourquoi elle renonce à employer ces moyens (ou des moyens équivalents) pour étudier la culture des dominés; et, la prenant au mot, je m'efforce de voir jusqu'où on peut aller dans la description du goût populaire en empruntant des concepts et des schèmes forgés pour l'analyse du goût dominant et en les transportant à l'autre bout de l'espace social. Ce qui pose, effectivement, un certain nombre de questions que nous avons déjà évoquées: l'espace social et l'espace symbolique sont-ils homogènes? Faut-il changer d'outils quand on passe la frontière qui sépare les manuels des non-manuels, les ouvriers des employés? Les différences entre dominants et dominés, entre culture dominante et culture dominée sont-elles de degré comme semble l'admettre ce transfert, ou de nature? En attribuant aux différentes fractions des classes populaires des "propriétés ", des équivalents des différentes espèces de "capital », ne va-t-on pas dans le sens des pseudo-théories de l'uniformisation culturelle et de l'embourgeoisement de la classe ouvrière ? Reste que cette transposition, par l'ironie involontaire qu'elle enferme, a au moins l'avantage de mettre les concepts et les schèmes usuels de la sociologie du goût à une épreuve dont ils sont ordinairement dispensés, et d'en faire voir les limites, et pour une part les présupposés, en les plaçant dans une situation difficile. Et puis, comme vous le dites, cette transposition produit, dans des conditions qui restent à examiner, un peu de connaissance, en opérant des distinctions et en établissant des variations là où on s'est habitué à voir de l'uniforme et de l'amorphe. Elle conduit au moins à se demander, quitte à choquer le sens des convenances qui règle la répartition des outils en fonction de la dignité sociale des objets, pourquoi ce qui passe pour du raffinement quand il s'agit d'opérer des distinctions et des nuances dans l'analyse des objets définis socialement comme les plus futiles de la culture dominante, serait, s'agissant des goûts populaires, d'avance disqualifié comme pinaillage ou comme glanage abandonné aux va-nu-pieds qui passent après la moissonneuse-batteuse théorique.

F. DE SINGLY.- Prenons le cas de la culture de métier. Peut-on vraiment la considérer comme un équivalent du capital culturel, qui n'est un opérateur de l'analyse sociologique que parce qu'il permet d'évaluer, de mesurer, d'ordonner? Ne devez-vous pas vous contenter de répertorier les différentes cultures de métier (du bâtiment, de la mécanique, du textile, etc.) comme des espèces juxtaposées et non hiérarchisables ?

C. GRIGNON.- Disons qu'il s'agit d'une analogie au second degré puisqu'aussi bien la sociologie des goûts dominants n'utilise elle-même qu'en un sens approché une notion empruntée à l'économie. Tout ce que l'on peut dire - mais c'est déjà un constat comparatif - c'est que la culture de métier compte plus, c'est-à-dire rend compte d'un nombre plus grand de pratiques, pour certaines fractions et certaines couches de la classe ouvrière, à savoir les ouvriers d'origine ouvrière et l'« élite ouvrière ", que pour d'autres, par exemple les ouvriers d'origine paysanne. À l'inverse, on peut montrer que le réseau de relations familiales à base locale compte davantage chez les ouvriers d'origine paysanne que chez les ouvriers d'origine ouvrière. Et l'on pourrait sans doute raffiner l'analyse et montrer que les différentes espèces de la culture de métier, qui se décompose elle-même en culture d'atelier, de chantier, d'usine ou encore en culture professionnelle et en culture d'apprentissage, correspondent à des ensembles de pratiques et de goûts différents. De ce que le schème est identique on ne peut déduire que le sociologue admet que les «propriétés » des classes dominées sont l'équivalent de celles des classes 
dominantes : je considère seulement que l'opposition entre le petit patrimoine, la petite propriété résiduelle et les savoirs professionnels ou les petites certifications scolaires peut jouer le même rôle dans l'étude comparative des goûts des différentes fractions de la classe ouvrière que l'opposition entre les différentes espèces de capital dans l'étude comparative des goûts des différentes fractions de la classe dominante. reconstruction d'objet par transposition de schéma théorique) se révèle, en sociologie, aussi féconde par ce dont elle rend compte directement que par ce que son inadéquation relative désigne indirectement. Ce n'est donc pas une objection à votre schéma que je voudrais formuler, mais le problème que seul le développement complet des présupposés de l'analogie, révélés par son passage à la limite, permet de poser. En matière d'« avoirs » sociaux et culturels, les petits avoirs fonctionnent-ils dans la même logique que les gros? Les différences de pratiques et de goûts mises en évidence par la comparaison entre " petits capitaux » développent-elles leurs effets, organisent-elles les interactions entre acteurs, livrent-elles leurs sens par référence aux mêmes enjeux, aux mêmes stratégies, aux mêmes règles que les différences qu'instaurent entre fractions des classes dominantes l'espace de jeu et les moyens procurés par la possession de "gros capitaux " sociaux et culturels? Autrement dit, joue-t-on à la même chose, se distingue-t-on au nom des mêmes principes, se différencie-t-on par rapport aux mêmes objectifs au sein des classes dominées et des classes dominantes? Votre transposition (celle qui vous amène à dire que les différences engendrées par les divers types de petites possessions ou par les différentes formes de contre-handicaps « jouent le même rôle dans l'étude comparative des goûts des différentes fractions de la classe ouvrière que l'opposition entre les différentes espèces de capital dans l'étude comparative des goûts des différentes fractions de la classe dominante »), une telle transposition, dis-je, risque toujours de remplacer l' homologie verticale à laquelle convie la tradition marxiste par une homologie horizontale tout aussi capable de s'ériger en clôture interdisant la prospection des espaces culturels qui échappent à cette prise déductive. Je ne dis pas que votre pratique de l'analyse des segmentations et des stratifications des classes populaires vous conduise à ne retenir que de petits principes de différenciation où ne se verrait plus que la force exténuée de celle qu'ils ont lorsqu'ils fonctionnent à plein ; mais précisément, puisque vous introduisez dans votre analyse des principes puissants de différenciation (écologiques, économiques, historiques, régionaux, etc.) l'analogie conceptuelle qui, en les faisant entrer dans le jeu d'une symbolisation sociale unifiée, les traite comme « capitaux » et, dès lors, ne peut plus en connaître que comme "petits capitaux » du seul fait qu'en tant que tels ils ne peuvent plus y apparaître que comme capitaux des " petits ", n'affaiblit-elle pas et ne dévoie-t-elle pas l'interprétation du sens que revêtent les différenciations internes aux classes populaires?

Il ne s'agit surtout pas de faire dévier le débat - comme un réflexe politique bien monté y inviterait - vers la fameuse question de savoir si une description trop fine de la segmentation et de la stratification de la classe ouvrière ne préjuge pas ipso facto de l'identité de nature entre différences intra-classes et différences inter-classes, voire si, par diablerie idéologique, elle ne serait pas faite tout exprès pour gommer la frontière entre classes dominantes et classes dominées. Toutes les fois où la sociologie a voulu lester d'un rien de contenu scientifique cette question venue de la théologie hégélienne, c'est elle qui s'est retrouvée en position de discipline théologique, occupée à distinguer les « contradictions principales » des « contradictions secondaires », quand ce n'était pas 
à discriminer l'«aspect principal» et l'«aspect secondaire» de la contradiction principale. Pour le sociologue les différences sont toutes et toujours bonnes à prendre, c'est-à-dire à décrire, y compris les différences entre différences. À d'autres et par des moyens qui ne peuvent être ceux de la sociologie le goût du « bilan global » ou le sérieux ecclésiastique dans le maniement du trébuchet à peser les « contradictions ». La question posée ici est plus simple et surtout plus urgente pour le sociologue, puisqu'elle conditionne les choix de son travail empirique : toutes les différences jouentelles identiquement quand elles ne s'instaurent pas entre les mêmes avoirs et les mêmes groupes? Nommer et construire identiquement leur principe d'interprétation engage déjà les choix de la description. Deux exemples de ce que l'homologie "capitalistique " généralisée risque de dissimuler lorsque sa formulation ne se retourne pas en évaluation critique de la description qu'elle procure.

Le premier, pourtant le plus favorable à l'application d'un schème unifié de comparaison inter- et intra-classes, celui de la continuité formelle de l'échelle ordinale entre niveaux scolaires, fait voir déjà une difficulté, c'est-à-dire l'effacement d'au moins deux différences : a) celle qui s'exprime dans la complète hétérogénéité sociale et culturelle des effets liés aux diplômes du haut et du bas de la hiérarchie scolaire; $b$ ) la différence de fonctionnement qui sépare les différences liées à la possession des différents titres de haut niveau, des différences liées à la possession ou à la non-possession des titres scolaires caractéristiques des classes populaires. Le CAP par exemple n'est décrit que fort inadéquatement dans sa différence avec un diplôme d'enseignement supérieur comme dans sa différence avec la privation de tout titre scolaire, lorsque, identifié à un degré du cursus, il est appréhendé comme possession d'un tout petit capital scolaire, implicitement comparable, sinon quantitativement du moins ordinalement, aux grands capitaux scolaires. La stratification et la segmentation des plus hautes certifications scolaires ne procurent pas seulement des indicateurs commodes dont l'ordre hiérarchique ou le parallélisme conflictuel sont inscrits administrativement dans l'institution scolaire; elles instaurent un champ social de la rareté culturelle dont la spécificité détermine dans les classes dominantes une gamme cohérente de pratiques stratégiques inter-agissant dans un jeu de la distinction et de la concurrence symboliques qui ne peut être joué que dans ce champ clos (pour ne rien dire des segmentations du marché de l'emploi sur lequel les changements de volume du capital scolaire changent radicalement les lois de la mobilité de ce capital). Les « petites certifications » ne correspondent, elles, que formellement (i.e. dans un organigramme) aux plus bas degrés de la même échelle; elles ne proposent ni des enjeux analogues ni un espace de comportement équivalent aux pratiques culturelles des classes populaires qui font assurément avec, mais tout autrement, par exemple plus sporadiquement. Les différences de chances ou d'attitudes qu'induisent les petits diplômes sont réelles, elles stratifient souvent nettement les groupes populaires, mais, n'obéissant pas à la même logique de différenciation que celles qui autorisent les fractions des classes dominantes à jouer des parties entières selon les règles programmées des interactions socio-scolaires, elles se trouvent fictivement ramenées à ce cas de figure lorsqu'on traite leurs effets (lectures, loisirs, style de vie quotidien, etc.) comme des effets "classiques" de la possession et de la non-possession d'un capital scolaire, fût-il petit. Il faut se défier de cet alignement généralisé de la sociologie de la culture sur la sociologie de la culture de certaines fractions des classes dominantes, par où ressurgit toujours la tentation simplificatrice de décrire l'ensemble de la société comme occupée à jouer, avec la même passion ou le même sérieux, à la même partie de 
Monopoly. Le raisonnement serait le même à propos des petits patrimoines économiques dont la possession suscite des stratégies de conservation ou d'augmentation, des utilisations économiques ou symboliques qu'on caricature ou mutile lorsqu'on n'y voit que la reproduction en « petit » des « grandes » stratégies patrimoniales.

L'hiatus d'intelligibilité est encore plus net si l'on prend l'exemple de compétences symboliques et techniques comme sont les cultures de métier, ou l'exemple de moyens de sociabilité et d'échange symbolico-économique comme sont les réseaux populaires de relations. Ne construit-on pas une fiction conceptuelle lorsqu'on rend compte dans le langage unifié des «avoirs » comparables (qui pour une " espèce » donnée de capital ne différeraient jamais qu'en volume) du rôle que jouent des maîtrises techniques et des compétences symboliques aussi différentes, par leurs fonctions comme par leur mode d'utilisation, que celles des classes dominantes et des classes dominées? Ne sont communs à ces « capitaux » ni les « terrains » ou les « marchés » sur lesquels ils sont mis en œuvre (marchés de l'emploi, du loisir, du mariage, de la sociabilité), ni les fonctions de cette mise en œuvre (modelés par des représentations différentes de la légitimité culturelle voire par son oubli ou sa dénégation) ni, bien évidemment, leurs ingrédients symboliques ou techniques comme leur « composition organique ». Il n'y a par exemple plus guère que le mot de «capital » qui soit commun à deux principes de différenciation aussi différents que celui qui commande les stratégies de la dissimulation culturelle gérées à partir de la possession des espèces de capital propres aux classes dominantes, et le principe qui est à l'œuvre dans la manière dont les différentes cultures de métier propres aux classes populaires conditionnent des transpositions de compétences, des orientations culturelles ou des chances différentes de "travail noir », de " perruque », ou de résistance à la déqualification professionnelle de l'image de soi, etc.

27 Je me répète peut-être, mais il me semble qu'on est sur la pente d'une injustice interprétative lorsqu'on se laisse aller à croire qu'il n'y a pas d'autre voie pour décrire comme « culture » l'univers réglé d'une partie de belote ou d'une conversation de bistrot, que celle qui consiste à lui appliquer des schémas et des mots qui doivent leur légitimité au fait d'avoir été empruntés à la description sociologique d'une conversation de salon ou d'une partie de bridge, démarche où il n'est jamais sûr que l'effet de légitimité scientifique ne doive rien au cheminement parallèle de la légitimité sociale: injustice interprétative inversée mais presque aussi grave que celle que l'ethnocentrisme fait à la description de ces interactions populaires lorsqu'il les renvoie au "primaire », à la " nature », à la pratique hors-règles. Vous connaissez comme moi ces exercices à la mode où l'application des réhabilitateurs à manifester ostentatoirement par l'emprunt des grands mots de la critique littéraire ou de l'anthropologie des profondeurs le "même " respect théorique à une œuvrette populaire qu'à un drame shakespearien est insupportable d'incompréhension sociologique pour les conditions réelles dans lesquelles celle-ci a été conçue et consommée : l'humour est toujours ambigu et il opère aussi bien au détriment des schèmes transposés que de l'objet de la transposition; si le lecteur cultivé est friand de ces effets de décalage, on peut être sûr que ce n'est pas seulement de sa propre culture qu'il sourit aussi complaisamment. On pourrait multiplier les exemples, la difficulté de description sur laquelle je veux attirer l'attention reste la même, dans les cas où la transposition produit des connaissances empiriques et dans les cas où elle ne produit guère plus qu'une autosatisfaction de dame patronnesse grimée en mandarin aux pieds nus. Bref, lorsqu'on transpose homologiquement un principe de description (un vocabulaire, i. e. à la fois une grille et un questionnement) qui a «marché » pour rendre 
compte de la segmentation culturelle des classes dominantes, il est difficile de ne pas transposer, en même temps que la distanciation déjà acquise par la construction transposée, quelque chose des intelligibilités qui se sont constituées sur et pour le terrain où le schéma a d'abord été appliqué.

J'admets volontiers que la transposition pince-sans-rire que vous opérez, celle où le «capital», la « ressource ", l'« inversion» ressurgissent de toutes parts pour faire la nique au "manque», provoque une rupture tant avec les pré-constructions de l'ethnocentrisme (savant ou spontané) qu'avec les constructions hiérarchiques et misérabilistes qui ne laissent plus aux pratiques populaires qu'un seul exercice symbolique, celui de lorgner bouche bée au-dessus de leur tête le dernier échelon de l'échelle des qualifications culturelles. En remettant tout le monde dans le coup, vous cassez la forme la plus brutale de hiérarchisation des symbolismes qui tend toujours à réduire toutes les différences à celle de l'avoir et du non-avoir : «Voyez», semblez-vous nous dire : " une théorie riche marche aussi sur les pauvres ». Mais, en montrant l'avoir dans le manque (certains avoirs qui dissimulent ou que constituent certains manques), en rendant par les mêmes mots justice et existence à des propriétés différentes, la continuité entre dominants et dominés que vous rétablissez par votre description et votre langage constitue aussi, vous le sentez bien, le terrain d'une re-hiérarchisation douce des avoirs sociaux; elle suggère une théorie des avoirs populaires qui ne serait autre chose qu'une miniaturisation de la théorie des avoirs légitimes. Les seules différences entre dominants et dominés seraient-elles de n'avoir que plus ou moins de la «même chose»? Toutes les « ressources » seraient-elles taillées de même étoffe?

C. GRIGNON.- Je pourrais évidemment vous répondre que la démarche que j'ai suivie est au moins consciente des objections que vous lui faites. Vous m'accorderez que j'ai bien essayé de montrer que "propriété » ne signifie pas nécessairement "avoir » et que la constellation de propriétés par laquelle on peut distinguer une fraction des classes populaires des fractions voisines se définit comme un système de relations entre des handicaps et des contre-handicaps, des contraintes et des ressources. Nous avons vu que chacun des traits de cette constellation est toujours à quelque degré ambivalent; l'aménagement du cadre et des conditions de vie - de la «niche de vivabilité » - consiste précisément à jouer sur cette ambivalence : «faire avec », c'est essayer de transformer des contraintes en ressources, des handicaps en contre-handicaps, etc. ou, défensivement, d'éviter que des ressources se transforment en contraintes. De ce point de vue, la distribution des différents types d'aliénation (qui font eux aussi partie des propriétés distinctives de chaque groupe) entre les différentes fractions de classe peut elle aussi être prise en compte pour décrire et expliquer les variations du goût populaire ; par exemple, «avoir » tel ou tel type de culture de métier, c'est aussi être soumis à tel ou tel type de rapport hiérarchique, à tel ou tel type de contraintes liées aux horaires, au bruit, à la pénibilité du travail, etc.

Mais j'avoue que cette défense ne me satisfait guère. Il faut le reconnaittre : la description du mode de vie et de l'ethos des classes dominées qu'autorise la transposition au cas de celles-ci des schèmes et de concepts forgés pour l'étude des classes et de la culture dominantes demeure inévitablement entachée de dominomorphisme. Dans la mesure ou l'on essaie de saisir ce qui se passe du côté et dans l'esprit des dominés par analogie avec ce qui se passe du côté et dans la tête des dominants, on risque effectivement, comme vous le dites, non seulement de mettre l'accent sur les ressemblances, mais, ce qui est plus grave, de manquer ce par quoi les dominés pourraient différer des dominants; en 
s'attachant à montrer que ce qui vaut pour les dominants vaut aussi pour les dominés, que ce qui explique le goût dominant peut aussi, pourquoi pas, expliquer le goût populaire, on s'expose à retrouver constamment le dominant dans le dominé, de la même manière que Darwin, comme le montre Canguilhem, retrouve l'homme dans l'animal, et, à la limite, à ne retrouver dans le dominé que du dominant. Opposer, par exemple, le conservatisme des ouvriers d'origine paysanne dotés d'un petit patrimoine au progressisme de l'élite ouvrière d'origine ouvrière est une manière de prêter aux dominés des dispositions à l'égard de la politique identiques à celles des classes dominantes, qui expose du même coup à manquer ce qui fait peut-être la spécificité de la relation que les classes populaires entretiennent avec la politique, à savoir un certain type, une certaine qualité d'indifférence, plus ou moins marquée selon les groupes et selon les moments; spécificité sur laquelle les descriptions d'inspiration misérabiliste mettent d'emblée le doigt, mais qu'elles appréhendent et interprètent d'une manière purement négative, en terme de manque d'intérêt, de manque de compétence, bref de distance au rapport dominant à la politique.

31 Il reste qu'il faut d'abord s'être donné les moyens de rompre réellement, c'est-à-dire empiriquement, avec le dominocentrisme, quitte à courir le risque de s'enfermer temporairement dans une description dominomorphique des cultures et des classes dominées, pour pouvoir ensuite décrire celles-ci dans ce qui les distingue radicalement mais positivement des classes et de la culture dominantes (et non plus seulement dans ce qui les oppose négativement à celles-ci). L'analogie avec le processus par lequel la pensée anthropologique, confrontée à la question des rapports entre l'homme et l'animal, s'est dégagée, par des ruptures successives de l'anthropocentrisme, puis de l'anthropomorphisme permet de saisir la succession des étapes par lesquelles doit passer la pensée sociologique confrontée à l'étude des "espèces sociales" et des cultures « inférieures ». De même que l'anthropologie pré-darwinienne repose sur l'idée d'une coupure radicale entre le règne humain et le règne animal (principe même de l'anthropocentrisme), de même la posture misérabiliste correspond à un état de la pensée sociologique où celle-ci n'est pas encore parvenue à rompre avec l'idée d'une séparation radicale et d'une différence de nature entre la culture des dominants et la culture (la «nature ») des dominés. On pourrait dire, pour paraphraser G. Canguilhem, que le préjugé qui la conduit à ménager pour les classes dominantes un règne séparé la conduit du même coup, comme on le voit nettement chez M. Halbwachs, à exclure les classes populaires de la sphère de la culture et même de la société. On ne peut songer à étudier les cultures populaires dans leur spécificité que si l'on s'est d'abord débarrassé de l'idée dominocentrique de l'altérité radicale de ces cultures (qui conduit toujours à les considérer comme des non-cultures, comme des «cultures-natures »; témoin la manière dont le misérabilisme appelle infailliblement le populisme); de même on ne peut poser pour de bon la question de l'hétérogénéité de l'espace social et de l'espace symbolique que si l'on s'est d'abord donné les moyens (ils valent ce qu'ils valent) de rétablir la continuité de l'espace social et de l'espace symbolique; on ne pourra songer à réintroduire dans l'analyse scientifique des cultures dominées le point de vue et l'expérience des dominés que si l'on est auparavant parvenu à inclure et à rapatrier les classes dominées dans la sphère de la culture. Bref, s'il est vrai qu'on se débarrasse plus facilement du dominocentrisme que du dominomorphisme, il reste qu'il faut sans doute passer par le dominomorphisme pour se débarrasser du dominocentrisme. 
32 qui imposent une démarche réglée à la construction des cultures populaires comme objet sociologique clôt ce que mon interrogation impliquait d'objection. J'aurais mauvaise grâce à résister à une analogie épistémologique qui prend $\mathrm{G}$. Canguilhem pour levier et Darwin pour point d'appui. Si je suis bien votre regard, je dois conclure que dans la phase actuelle de la construction de l'objet « goût populaire », toute démarche conceptuelle qui réintègre les classes populaires à une problématique générale de l'analyse culturelle, au lieu de prendre le risque de les exclure en les spécifiant dans une altérité qui a tôt fait de se remplir de vide et d'homogénéité, a au moins le mérite de se garder du danger majeur de dominocentrisme, quitte à emprunter les voies du dominomorphisme. Mais ne peut-on pas dire alors que l'on gagne déjà quelque chose dans la difficile rupture avec le dominocentrisme lorsque l'on rompt avec la sociologie spontanée des dominants qui réfère toute différence culturelle à l'opposition entre choix de liberté et pressions de nécessité, bref, à l'opposition entre "goûts » (réservés aux dominants) et non-goûts (lot des dominés), pour y substituer une opposition entre "goûts de liberté » et "goûts de nécessité » qui reconnaît également la dimension du "goût », et donc du choix, aux pratiques culturelles des classes dominantes et à celles des classes populaires? Je pose la question parce que votre texte de la Revue française de Sociologie semblait bien détecter quelque odeur de dominocentrisme dans cette opposition théorique.

C. GRIGNON.- C'est qu'il ne suffit pas de parler de "goût de nécessité » pour reconnaître aux goûts populaires toutes les dimensions du goût et pour rompre réellement avec le dominocentrisme. Tant qu'elle reste en deçà de cette rupture, la sociologie du goût ne peut pas davantage penser le goût populaire que la culture populaire ; comme il lui est difficile de proclamer "officiellement » que les classes populaires n'ont pas de goût et qu'elle ne peut faire moins (sous peine de se faire pincer en flagrant délit d'ethnocentrisme de classe) que de se démarquer de l'opposition spontanée entre «bon goût » et " non-goût », elle essaie de se tirer d'embarras en mariant de force le " goût » et la " nécessité ». Mais voyez le nouvel embarras dans lequel la plonge ce qu'elle appelle les "paradoxes» du "goût de nécessité». Les analyses qui opposent les "goûts de nécessité » (du côté des classes populaires) aux "goûts de liberté » (du côté des classes dominantes) doivent toujours faire mine de réintroduire un peu de liberté dans la nécessité (pas assez «nécessaire » pour s'accomplir elle-même) sous peine de se trouver elles-mêmes dans la triste nécessité de reconnaitre que le goût de nécessité n'est pas du tout un goût, mais une réponse mécanique à un système de contraintes, ou plus exactement à un système de limitations réduisant à néant les possibilités de choix (nous retrouvons notre schéma de la « culture du pauvre » comme culture plus pauvre : l'éventail des choix se réduit quand on passe des classes dominantes aux classes moyennes et se referme brusquement quand on franchit le fossé qui sépare les classes moyennes des classes populaires). De deux choses l'une : ou bien les ouvriers ont eux aussi, si peu que ce soit, le " choix » - par exemple le choix, à coût égal, entre manger des haricots (en grains) ou manger des pommes de terre (bouillies) - et leurs goûts sont des "goûts de liberté ", de même nature (sinon au même degré, mais là n'est pas la question) que ceux des gastronomes des classes dominantes qui balancent entre le homard et la langouste, entre Taillevent et l'Archestrate. Ou bien les ouvriers n'ont pas le choix : ils doivent manger des haricots et pas autre chose (supposons que cette année-là les pommes de terre soient hors de prix) ; et dans ce cas, on n'a aucunement besoin de faire intervenir leur "goût » éventuel pour les haricots pour expliquer qu'ils mangent des haricots puisque, coincés 
comme ils le sont entre la nécessité biologique (c'est ça ou mourir de faim) et les limites de leur porte-monnaie (c'est ça et rien d'autre), ils sont de toute façon forcés de manger des haricots. J'avoue que les haricots de la Distinction me font penser aux épinards de Nino Ferrer (qui les a, je crois, trouvés dans le panier du « Garçon » de Flaubert) :

« Mon frère n'aim' pas les épinards

Et c'est heureux pour mon frèr' car

S'il les aimait il en mang'rait

Et i'n'peut pas les supporter. »

Il ne suffit pas de faire circuler les mêmes mots de part et d'autre de la barrière qui sépare les classes populaires des autres classes pour rétablir la continuité de l'espace social et de l'espace symbolique. On montrerait sans peine que chacun des termes usuels de la sociologie légitimiste des goûts perd son sens ou se trouve à tout le moins dévalué, amputé de la majeure partie de son pouvoir de signification quand il franchit la frontière en direction des classes dominées. En deçà de la frontière, la notion de goût recouvre une gamme très étendue de significations; elle désigne à la fois (et parfois indifféremment) des penchants, des habitudes, des préférences, des choix; elle renvoie tantôt à des déterminants cachés, aux dispositions profondes liées à la position et à la trajectoire sociale, tantôt à la partie émergée et visible des goûts, à des stratégies actives et conscientes d'ostentation et de distinction; le goût peut aussi bien, à la limite du sociologisme, se trouver réduit aux indicateurs extérieurs du goût, c'est-à-dire aux consommations et aux pratiques, que désigner aussi (ou parfois seulement) le rapport, plus ou moins distancié, que les acteurs entretiennent avec leurs pratiques. Au-delà de la frontière, le "goût » ne désigne plus que l'intériorisation, réaliste ou mystificatrice, du fatum social ; il n'intervient que pour refléter et redoubler des mécanismes d'exclusion. Le «penchant » ne désigne plus que la «disposition » à pencher d'avance du côté où l'on doit tomber; l'« habitude » se confond avec la routine, avec le train-train, le "goût» devenant une simple émanation, sans conséquence pour l'explication, du «cela va de soi » de la vie quotidienne. Des différents rapports que les membres des classes populaires peuvent entretenir avec ce qu'il leur revient d'avoir et de faire, la sociologie légitimiste du goût ne peut et ne veut retenir que l'adhésion résignée et non distanciée, rejoignant ainsi, à la limite de sa dérive, les lieux communs par lesquels les dominants se consolent sans trop de peine du sort des dominés (" que voulez-vous, ils sont heureux comme ça ", " c'est ça qu'ils aiment ", etc.). L'introduction formelle du vocabulaire des goûts dans la description légitimiste des pratiques populaires ne peut procurer que l'illusion de la rupture avec le dominocentrisme. On trouve un bon indice du fait que l'analyse reste en réalité en deçà de cette rupture dans le passage du misérabilisme au populisme que favorise ce glissement du vocabulaire : on passe aisément de l'idée selon laquelle les classes populaires sont bien forcées d'aimer ce qu'on leur abandonne à la célébration du goût populaire comme "goût en-soi ", goût du monde comme il est, si ce n'est comme il va, bref comme « goût naturel » par opposition au « goût artificiel » des bourgeois blasés et des intellectuels «trop » cultivés. Ce n'est sans doute pas un hasard si le goût du «Peuple» pour la « Nourriture», symbole de la «substance» et de la satisfaction des « besoins primaires » sert de motif privilégié pour l'illustration du " goût de nécessité ».

J.-C. PASSERON.- Mais quelle conclusion tirer de cette limitation du pouvoir descriptif et interprétatif de la théorie de la légitimité culturelle ? De l'existence de ce mur à la fois opaque et réfléchissant sur lequel celle-ci vient buter toutes les fois où elle prend directement pour objet quelque aspect des cultures populaires? Le retour à la case " départ », celle du populisme, est exclu; le relativisme culturel se dégrade en populisme 
quand la bonne volonté de réhabilitation le rend aveugle à l'hétéronomie symbolique que les rapports de domination introduisent dans le fonctionnement des cultures populaires ; et il devient ipso facto théorie de la légitimité culturelle quand il est capable de relativiser ses autonomisations méthodologiques. Bref, l'ethnocentrisme, en l'occurrence le dominocentrisme, resurgit dans ce jeu théorique dès que l'un quelconque des partenaires cesse d'avoir raison contre un autre, ce qui se produit nécessairement à chaque coup.

Il me semble que votre propos, fondé sur les mérites épistémologiques que vous accordez sous caution au dominomorphisme comme instrument capable d'assurer la rupture avec le dominocentrisme, tend à suggérer qu'il faut restituer, réellement et non fictivement, aux pratiques populaires, et donc aux opérateurs conceptuels qui supportent leur analyse, les caractéristiques pleines et entières d'un symbolisme c'est-à-dire toutes les dimensions d'un "goût » et d'un "style »: donner et retenir ne vaut. Tout à fait d'accord, puisque c'est, en matière de théorie du symbolisme, le minimum incompressible d'invariance que doit se donner toute analyse des variations culturelles qui refuse de réduire au degré zéro - au néant descriptif - un des états de la variation. La distinction entre "goûts de nécessité » et "goûts de liberté " dont vous venez de montrer l'ambiguïté théorique consiste bien à ruser dans le langage de la description avec des significations sociales contradictoires afin de conserver conjointement les bénéfices logiquement incompatibles du pouvoir descriptif que porte le questionnement dominomorphique et de l'évidence socialement toute-puissante que procure au lecteur son propre dominocentrisme. Le mixte final d'effet de connaissance et d'effet social de persuasion ainsi produit témoigne en tout cas que le discours sociologique restitue par ce choix plus facilement l'image et la fonction des goûts dominés dans le fonctionnement du goût dominant que la diversité et les principes de diversification des goûts dominés. Pour dire complètement la violence symbolique qui est faite par l'ordre social aux symbolismes dominés, la théorie de la légitimité culturelle s'expose à toujours répercuter quelque chose de l'opposition dominante entre « goût » et «non-goût ", à faire un «bout de chemin » énonciatif (mais qui peut mener loin) en s'appuyant sur une opposition descriptive qui est celle-là même à travers laquelle s'accomplit la violence symbolique qu'elle vise à objectiver. Autrement dit, lorsqu'il s'agit de dire la différence entre goûts dominants et goûts dominés, la théorie de la légitimité est conduite, par le langage des constats de force qui fait sa force théorique, à emprunter au seul langage de la différence de goût qui soit constitué, parce qu'il est dominant, une structure de description des différences symboliques qui ne peut qu'abolir la description d'un des deux termes de la différence dans le mouvement même par lequel elle veut en rendre compte. L'ambiguïté sur laquelle vous mettez le doigt livre donc à la fois une vérité et une illusion sociologiques, une duplicité de la réalité sociale qui se lit en miroir dans le double jeu verbal du sociologue qui doit estomper le rapport entre ce qu'il énonce au style direct de la vérité scientifique et ce qu'il énonce au style indirect en laissant parler dans ses phrases le discours social du goût dominant.

Embarqué dans cette galère théorique, le sociologue de la légitimité culturelle qui entend rendre compte de la culture illégitime est condamné à s'exprimer dans un discours mixte qui ne peut qu'éluder une règle exigible de tout discours scientifique, celle de rendre partout et toujours discernables les énoncés où le sociologue parle en son nom propre et ceux où sa phrase reproduit les énoncés qu'il prend pour objet de son énonciation. Soyons clair : je ne pense pas que l'analyse culturelle puisse éviter le recours au style indirect, guillemeté ou non. Songeons à la manière dont une bonne description ethnologique (ou aussi bien la Wertanalyse de Weber) doit, pour réussir à décentrer son lecteur, accepter de 
recourir aux catégorisations et aux mots de la "théorie indigène » dès lors qu'elle vise à construire un discours interprétatif qui doit à la fois faire repenser cette théorie première dans une théorie savante et transmettre au lecteur les moyens de penser, au moins approximativement, comme on pense dans la théorie indigène. L'inclusion du style indirect dans le style direct, voire les passages répétés de l'un à l'autre, sont de bonne instrumentation descriptive (ne bondiront à cette affirmation que ceux qui ont une conception formaliste ou naturaliste des assertions sociologiques). Hoggart par exemple tire une bonne part de son efficacité, dans l'objectivation du style de vie des classes populaires, de l'aptitude de sa phrase à lester les descriptions de comportements, énoncées par l'observateur en son nom propre, des mots (porteurs d'évaluations et de catégorisations) qui sont ceux par lesquels s'expriment habituellement les groupes sociaux observés. Mais vous avez raison d'attirer l'attention sur le fait que l'emboîtement du style indirect dans le style direct ne produit ni les mêmes effets scientifiques ni les mêmes effets sociaux de persuasion clandestine selon qu'il emprunte son pouvoir de structuration et de signification au goût dominant ou au goût dominé pour décrire soit l'un soit l'autre. Il y a un des quatre cas de figure possibles où le discours sociologique serre d'un peu trop près le langage de la domination symbolique pour ne pas être suspect de lui faire une "fleur", voire de lui conter fleurette: c'est évidemment le cas où, choisissant de donner, en style indirect, la parole aux mots d'une culture indigène pour parler d'une autre en les accueillant dans les énonciations au style direct de la théorie savante, il prend le risque supplémentaire de choisir comme prête- et porte-parole la culture indigène qui a déjà la voix la plus forte pour parler de celle qui ne dispose pas de cette volubilité expressive. Lorsque le glissement insensible entre style direct et style indirect redonne trop souvent la parole au goût dominant pour parler du goût dominé, cette technique de description ouvre, dans la communication sociale par l'écrit, des possibilités trop mouvantes de dédoublement pour l'objet décrit, le statut de la description et l'identité $\mathrm{du}$ descripteur. Ce constat n'est qu'une autre manière d'apercevoir que la théorie de la légitimité culturelle ne détient pas la clé empirique de la sociologie des cultures populaires puisque le procédé de description qui lui est lié et qui reste de facture classique quand il s'agit de décrire les cultures dominantes engendre ici au travers de la description in effigie des cultures dominées un jeu avec le lecteur qui fait songer à celui du chat et de la souris ; le chat est toujours gagnant puisque l'auteur peut toujours sembler dire ce qu'il ne dit pas mais qu'il sait pourtant que le lecteur des classes dominantes sera trop heureux d'entendre - pourvu qu'on parle de l'Autre - dans le moment même où l'auteur peut dire qu'il ne dit que ce qu'il dit. À ce registre indissociablement semi-direct et semi-indirect de la description, le dominocentrisme du lecteur, nécessairement cultivé, est trop puissamment sollicité pour résister longtemps à la tentation de virer au compte de la vérité scientifique des énoncés assumés en son nom propre par le sociologue une bonne dose de significations déjà toutes constituées qu'il reconnaît dans les citations qu'on fait complaisamment de son ethnocentrisme. Dans cette «liaison dangereuse » avec le lecteur, la rouerie du texte consiste à laisser à l'ingénuité du lecteur, en même temps que la charge du contresens à la fois bien et mal venu, la responsabilité d'opérer lui-même le geste coupable: la pure et simple légitimation, au nom de la science, du discours spontané que le goût dominant tient sempiternellement sur le non-goût des dominés.

38 P. Parmentier.- Puisqu'il est question de style, je prends le mot au vol et j'aimerais demander s'il n'y a pas une présupposition qui a l'air implicite dans le débat, à savoir que la stylisation constitue le tout du style, ce qui revient souvent à réserver en sociologie de la 
culture l'analyse stylistique aux exercices de style les plus repérables comme tels, la «broderie symbolique " sur fond de liberté de jeu, le loisir cultivé ou mondain par exemple, parce qu'ils se manifestent dans des conditions de distance à la nécessité économique, qui sont celles des classes dominantes.

J.-C. PASSERON.- C'est bien le problème que pose le projet de restituer dans l'analyse - et par conséquent dans les questions et les méthodes qui construisent les données permettant cette analyse - "toutes les dimensions d'un style» aux variations des pratiques et des goûts populaires. On dit facilement "style de vie ", y compris pour les classes populaires ; mais quand, dans le fait, on se contente de décrire un «mode de vie » la concession n'est guère que lexicologique. Tirer toutes les conséquences de l'hypothèse que le concept de style peut aussi organiser la description des pratiques populaires, y compris les plus contraintes ou les plus techniques, est peut être une gageure mais c'est bien le programme d'une sociologie des pratiques populaires qui entend leur reconnaître toutes les dimensions de la pratique symbolique. Identifier les "modèles" ou les régularités qui typent un mode de vie populaire, c'est seulement, si on se guide sur l'analogie linguistique, décrire la grammaire du comportement populaire. Ou bien l'on assume la thèse que le concept de style ne s'applique pas aux pratiques populaires, et il faut alors affirmer que la lot de nécessité permet de les déduire mécaniquement d'impératifs et de contraintes ; ou bien l'on prend au sérieux la dimension symbolique des pratiques populaires et - quitte à élargir et à transformer la notion de symbolisme - on s'oblige à décrire comme choix les variations de pratiques ainsi que leurs fonctions expressives, bref on se donne les moyens d'une description stylistique. Puisqu'il n'y a de style que là où se trouve disponible une gamme de choix, le problème n'est pas de gloser l'étendue de ces choix ou de chipoter sur le caractère inattendu du terrain où ils s'effectuent, mais d'identifier les paradigmes de l'exercice des variations possibles. Si toute une part de la sociologie misérabiliste des classes populaires dénie l'existence de paradigmes proprement populaires d'expression ou d'effectuation, c'est bien sûr au nom de la sur-attention qu'elle porte obsessionnellement au poids des déterminismes et à l'étendue des limitations pesant sur une condition dominée, mais c'est aussi sans doute par soumission aveugle au dominocentrisme qui engage à ne connaître qu'une forme de stylisation des pratiques, celle précisément qui se laisse aisément reconnaître à ses terrains privilégiés d'application, puisqu'elle est à la fois forme et matière des choix stylistiques que le style de vie des classes dominantes exhibe comme tels. Lorsqu'il s'agit pour le sociologue de dire les choix stylistiques qui s'expriment dans une «culture pratique ", cela ne se dit pas aussi facilement - le sens offre moins de prises verbales à la verbalisation - que lorsqu'il s'agit de dire les choix d'une production verbale ou d'une pratique bavarde, par exemple ceux d'une culture lettrée ou artistique, la «broderie symbolique » d'un code mondain ou d'une conduite ostentatoire, qui disent et ressassent les paradigmes de leurs choix - faisant ainsi par leur auto-commentaire plus qu'à moitié le travail du sociologue de leur style.

Plus précisément, si l'on examine comment, de l'Antiquité à la stylistique moderne en passant par Dumarsais et Fontanier, la description du style n'a pu construire progressivement son objet qu'en le définissant en termes de choix laissés ouverts par la langue - i.e. en identifiant ses "figures» en termes d'écarts substitutifs - la longue hésitation et les contradictions des sémanticiens et des rhétoriciens autour de la définition de la norme qu'il faut bien situer quelque part pour définir la substitution qui fait figure, révèle un parallélisme frappant entre les problèmes posés par l'exploration de 
la dimension symbolique des pratiques, linguistiques ou non : qu'il s'agisse de parlure ou de culture, l'utilisation de concepts comme ceux de «style » ou de "goût » a d'abord et spontanément tendu à mettre le Peuple en position de porteur éponyme du non-style comme du non-goût. Puisqu'il faut logiquement un point fixe qui soit en même temps un point zéro auquel rapporter pour les caractériser les choix constitutifs d'un style, il suffisait de laisser jouer la logique de la hiérarchisation sociale pour voir le peuple (l'usage populaire, les mœurs populaires) s'offrir spontanément à venir occuper cette position "commune ", ce lieu sans qualités qui permet de définir toutes les qualités. Le fonctionnement du symbolisme dominant se nourrit pour formuler ses choix comme choix stylistiques de l'exploitation symbolique des pratiques populaires comme forme nulle du symbolisme : la sociologie misérabiliste des cultures populaires n'est que l'écho sur le mode déploratif de ce dominocentrisme premier. Contre toute évidence linguistique, la stylistique a ainsi longtemps tourné autour de l'idée commode d'une formulation " simple et commune » qu'il serait encore plus commode d'immobiliser dans un " usage " socialement reconnaissable de l'expression "commune", à savoir l'usage populaire. Il est frappant de constater que, pour sa part, la stylistique n'a pu préciser rigoureusement la fonction substitutive du choix de style à travers le concept de figuration, sans découvrir en même temps que l'expression populaire fournissait en abondance des exemples de toutes les figures qu'elle répertoriait ainsi. La même conversion est-elle vraiment impossible à la sociologie? S'il se fait, comme le répète Gérard Genette après Boileau, « plus de figures en un jour de halle qu'en plusieurs séances d'Académie » (et aussi plus de phrases grammaticalement acceptables dirait Labov, après Malherbe), est-il si difficile de faire l'hypothèse qu'il se fait autant de «broderies symboliques", de choix expressifs ou efficaces dans les comportements techniques ou pratiques des classes populaires que dans les séances de stylisation qu'organise l'appareillage culturel des classes dominantes? Il est parfaitement compréhensible que la stylistique spontanée des classes dominantes préfère s'en tenir à une définition du style qui leur permette de goûter le leur par différence avec l'absence de style qu'elles incarnent dans l'image-repoussoir d'un enchainement mécanique ou machinal de gestes ou de mœurs qui seraient le propre des classes populaires ; mais la sociologie pourrait, elle, ne pas calquer sa définition du style et de la stylisation sur une image à la fois aussi restrictive et aussi machinale. Bref, pour rester dans le fil de l'analogie linguistique, on pourrait dire que la sociologie des classes populaires n'est pas condamnée, dans la description de leur culture, au triste catalogue des «tropes non-figures » (c'est-à-dire des tropes qui sont des choix d'expression «forcés » et qui sont imposés au locuteur parce que sa langue ne possède pas le mot propre); il suffit sans doute à la sociologie d'y aller voir pour recueillir elle aussi une ample moisson de "tropes-figures " (c'est-à-dire de tropes faisant figure parce qu'ils résultent du choix d'un mot au lieu et place d'un autre).

C. GRIGNON.- Derrière toutes les réticences à appliquer le concept de style au mode de vie populaire, on trouve la certitude dominocentrique qui conduit inévitablement à se poser (et à résoudre en termes de hiérarchie sociale) la question du degré auquel les modes de vie des différentes classes méritent d'être appelés des styles de vie. Soit, sur ce point, quelques remarques en forme de contre-propositions, pour compléter ce qui a été déjà dit lors de la première séance sur la relation entre les aspects pratiques et les aspects stylistiques de la culture populaire.

42 1. Les classes dominantes ne sont pas les seules à avoir un «style de vie pour-soi » (elles n'ont pas le monopole de la stylisation de la vie). La cécité aux formes spécifiques que 
prend la stylisation dans les classes populaires est l'indice du degré auquel l'ethnocentrisme de classe conduit à dénier la qualité de style aux pratiques qui accumulent, du point de vue du goût dominant, les fautes de style. Si l'on entend se placer d'un point de vue strictement sociologique, on ne peut que réduire le style de vie aux pratiques par lesquelles les agents s'efforcent de styliser leur vie, c'est-à-dire de mettre les différents aspects de leur vie (alimentation, habillement, logement, etc.) en conformité avec les modèles qui n'émanent pas nécessairement de la culture dominante et qui, lorsque c'est le cas, n'émanent pas toujours de la sphère de la légitimité. On a déjà montré, en prenant l'exemple des sous-cultures adolescentes, que la stylisation de la vie peut se réaliser, dans les classes populaires, par référence à des modèles autochtones, ou suffisamment retraduits et retravaillés pour être considérés comme tels (comme c'est le cas pour les modes vestimentaires) ; ainsi le travail de stylisation accompli par les juniors des classes dominées consiste à marquer, c'est-à-dire à "déstandardiser » les objets standards (voitures, « mobs », jeans, etc.) qu'ils parviennent à s'approprier pour leur faire dire, entre autres, cette appropriation et leur appartenance au groupe auquel leur propriétaire appartient ou essaie d'appartenir. Les classes dominantes n'ont pas davantage le monopole de la stylisation visant à brouiller les indices extérieurs de l'appartenance de classe ni du jeu avec l'identité sociale. Le cas de l'architecte, du journaliste ou du chercheur en sciences sociales qui « s'amuse » à changer de personnage en se donnant le look d'un paysan ou d'un " prolo » ne diffère pas, sous le rapport de la stylisation, de celui du travailleur immigré qui dissimule son casse-croûte dans un attaché-case ou qui, au sortir de l'usine, troque le bleu non contre le jean mais contre le costume et la cravate : comédie dans un cas, drame dans l'autre, sans doute; mais il n'y a pas moins de «jeu», ne serait-ce qu'au sens où l'on parle du jeu de l'acteur, dans le second que dans le premier.

2. Le mode de vie des classes dominantes ne constitue pas moins un «style de vie en-soi » que celui des classes dominées. Si l'on entend par style le résultat de l'opération de stylisation réalisée non plus par les agents mais par un observateur extérieur, il faut admettre que tout style de vie est, pour une part, un style de vie en-soi, c'est-à-dire, en fait, un style de vie pour-autrui. Les dominants n'échappent pas au regard, par définition critique, des dominés. La prédilection du sociologue légitimiste pour l'étude des goûts et du mode de vie dominants suffit à transformer ceux-ci en style de vie en-soi (même si le sociologue est évidemment enclin à reconnaitre de préférence la qualité de style aux modes de vie qu'il parvient le mieux à styliser). En effet la catégorisation savante des goûts dominants ne diffère pas, sous ce rapport, de l'observation des types populaires à laquelle se livre l'amateur de pittoresque social: le sociologue et le curieux populiste essaient tous deux, chacun à sa manière, de reconnaître des figures et si possible une configuration dans un ensemble de traits qui, sans leur intervention, demeurerait amorphe.

Par style de vie en-soi on peut entendre aussi le style de vie subi, la forme que le mode de vie reçoit de l'extérieur, sous l'action des conditions matérielles d'existence et des contraintes de la vie sociale et qu'il ne prend que pour un observateur extérieur, à l'insu des agents. L'opposition entre le style de vie en-soi des classes populaires et le style de vie pour-soi des dominants (qui dans l'inversion populiste devient l'opposition entre l'«authentique » et l'« artificiel») repose sur la tendance ethnocentrique à ne bannir le sujet que lorsqu'il s'agit des classes populaires - réduites au rôle de figurants - et à le réintroduire dès qu'il s'agit des classes dominantes, à la fois comme sujet agissant 
- acteur - capable de modeler son mode de vie sur des modèles et au besoin d'en inventer, et comme sujet observant, capable et seul capable de reconnaître et de conférer du style aux manières d'être «typiques » des classes populaires. Dans la mesure où il adopte ce point de vue, le sociologue a toutes les chances de contracter la cécité des dominants à l'égard de leurs propres stigmates. De même que la linguistique spontanée des classes dominantes constitue l'accent dominant comme absence d'accent, accent zéro par rapport auquel les accents régionaux ou populaires s'entendent et se définissent comme des déformations plus ou moins pittoresques, de même la stylistique spontanée des modes de vie tend à constituer les marques dont les dominants sont porteurs (et qui disent à la fois la domination et les contraintes liées à l'exercice de la domination) comme des nonmarques, à partir desquelles se voient les déformations des corps et des visages populaires. Pour l'analyse stylistique, qui doit en tant que telle demeurer indifférente aux fonctions sociales de domination des marqueurs, il n'y a pas lieu de faire un sort différent à des stigmates comme le bronzage du loisir ou le masque de l'autorité et à des stigmates comme le hâle du travail ou la mimique de l'obsequium.

3. L'opposition entre le style de vie dominant et le style de vie dominé n'est pas homologue de l'opposition entre l'utilitaire et le gratuit (ou entre le "nécessaire » et le "superflu», la "fonction » et la "forme ", et plus généralement entre tous les termes construits par dérivation sur l'opposition entre "goûts de nécessité " et "goûts de liberté »). On ne peut évaluer le degré de stylisation ou de « stylité » d'un mode de vie par rapport à ces critères sans se référer à des choix d'ordre esthétique : prendre parti dans le débat entre les tenants et les adversaires du "style fonctionnel " est une question de goût, pas une question de sociologie. On montrerait sans peine que les classes populaires peuvent avoir elles aussi le goût du superflu et de l'inutile. Quiconque connait les intérieurs populaires sait que les bibelots peuvent envahir le "séjour" comme les gadgets peuvent envahir la cuisine; moins souvent achetés qu'offerts (à l'occasion d'anniversaires, de la fête des mères, etc.), ils constituent même un bon indicateur d'intégration de la famille et de l'étendue du réseau de relations. Inversement l'histoire récente de la mode montre que celle-ci est dominée, que ce soit en matière de costume ou d'ameublement, par la montée du "fonctionnel » et le déclin de l'ornement. Sauf à faire intervenir des jugements de valeur ultimes et à reconnaître qu'il ne parle pas autrement qu'un esthète de loft ou qu'un commissaire-priseur, le sociologue ne peut pas prétendre que l'utilitaire sans style devient le style fonctionnel quand on passe des dominés aux dominants ; l'amateur de high-tech ne joue pas davantage de la relation entre forme et fonction que l'ouvrier qui bricole une table basse à partir d'une roue d'auto.

4. On ne peut reconnaitre la dimension stylistique des modes de vie populaires que si, écartant à la fois la représentation dominante du style comme improvisation libre, abandonnée à l'initiative et au don personnels des individus, et son corollaire, la représentation $d u$ non-style comme exécution mécanique d'une partition ou d'un programme, on s'attache à décrire la relation entre les pratiques des agents et les contraintes liées à la condition et au milieu en termes d'interprétation. On pourrait sans doute dire de la contrainte ce qu'André Varagnac disait de la tradition: elle place le « sujet agissant non pas devant un modèle à décalquer mais en face du réel à maîtriser grâce à l'exemple de précédents succès [...] L'essentiel n'est pas de répéter mais de réussir ${ }^{6}$ ». L'idée que le style disparaît à mesure que la liberté décroît et que l'étau de la nécessité se resserre repose sans doute sur une image de la robotisation intégrale des pratiques populaires qui hante aussi bien les descriptions misérabilistes de la sociologie du goût que 
la métaphore halbwachsienne de l'ouvrier-matière ou la métaphore marxienne de l'ouvrier-machine. De fait, on ne pourrait plus parler de style si les pratiques des agents étaient réellement des réponses automatiques à des automatismes, si leur mode de vie se réduisait à l'exécution machinale d'un programme répétitif inscrit dans une condition complètement taylorisée. Mais le logement populaire ne se laisse pas réduire à l'usine à habiter souterraine de la Metropolis de Fritz Lang, pas plus que l'alimentation populaire à la machine à manger des Temps modernes. La taylorisation du travail elle-même se définit comme une tentative utopique pour amener les serviteurs de la machine à n'être plus que de simples exécutants: elle ne se réalise que lorsque la production a été entièrement automatisée et que les derniers interprètes humains ont cédé la place aux robots. L'image du match ou de la bagarre, où le style, comme science du geste ajusté, virtuosité proleptique, capacité à déchiffrer et à prévenir les intentions et les coups do l'adversaire, est la condition même de l'action efficace, donne sans doute une idée beaucoup plus juste de ce que peut être le style d'un mode de vie confronté à l'urgence et à des contraintes brutales.

47 J.-C. PASSERON.- Bon, restons-en là pour cette fois.

\section{NOTES}

1. M. Halbwachs, La classe ouvrière et les niveaux de vie. Recherches sur la hiérarchie des besoins dans les sociétés industrielles contemporaines, Paris, F. Alcan, 1912, XVII-495 p.

2. Id., Esquisse d'une psychologie des classes sociales, Paris, Marcel Rivière, 1964, p. 167-179.

3. Id., La classe ouvrière et les niveaux de vie, Paris, Gordon \& Breach, 1970, réimp., p. 413.

4. Ibid., p. XIII.

5. C. Thélot, Le poids d'Anchise. La mobilité sociale en France, Nantes, INSEE, 1980, p. 125 (document de travail).

6. A. Varagnac, Civilisations traditionnelles et genres de vie, Paris, A. Michel, 1948, p. 303. 